\title{
Heuristic Optimization of Supplementary Controller for VSC-HVDC/AC \\ Interconnected Grids Considering PLL
}

\author{
Elyas Rakhshani, ${ }^{1,2}$ Kumars Rouzbehi, ${ }^{2}$ Mohamed Atef Elsaharty, ${ }^{2,3}$ and \\ Pedro Rodriguez Cortes ${ }^{1,2}$ \\ ${ }^{1}$ Abengoa, Abengoa Research, Seville, Spain \\ ${ }^{2}$ Department of Electrical Engineering, Technical University of Catalonia (UPC), Barcelona, Spain \\ ${ }^{3}$ Arab Academy for Science, Technology, \& Maritime Transport, Alexandria, Egypt
}

\section{CONTENTS}

1. Introduction

2. Interconnected AC/DC System

3. Design of Supplementary Power Modulation Controller for the VSC-HVDC Link

4. Dynamic Effects of Frequency Measurements

5. Parameters Tuning for SPMC by Heuristic Methods

6. Simulation Results

7. Conclusion

Funding

References

\begin{abstract}
This paper presents a new approach to enhance the dynamic responses of $\mathrm{AGC}$ in power systems by means of heuristic optimization of VSC-HVDC supplementary controllers. The upcoming power electronics-based VSC-HVDC transmission systems offer new features that would be advantageous for improving the frequency control and thus for enhancing the stability of the transmission grids. In this paper, the parameters of the proposed control modulation are tuned using Genetic Algorithm and Simulated Annealing methods. The performance of the proposed intelligent based tuning approach is assessed through MATLAB simulations for an AC/DC interconnected system. For the sake of detailed analysis, the effects of PLL and frequency measurements are also included in the VSC-HVDC system modeling. Furthermore, to show merits of the proposed strategy, a comparison between AC and DC transmissions is presented.
\end{abstract}

\section{INTRODUCTION}

Advancements in power electronic equipment and the solutions with VSC-HVDC technology have great potentials to manage modern power systems with better stability and more transmission capacity. This issue becomes more important especially when new trends like AC power deregulation and competitive markets with high penetration of power electronic-based equipment in the modern power systems are taken into account [1]. These new developments in the power system restructuring require innovations in various parts of the power system, especially in the transmission networks, as its reliability plays a critical role in this new deregulated environment $[2,3]$.

The need for transmitting power over long distances with lower losses and higher stability of the grid has been always among the main challenges [4-6].

In modern power systems with high penetration of renewable resources, a long distance transmission for transferring the power between synchronized or unsynchronized areas will
Keywords automatic generation control, load frequency control, genetic algorithm, power system modeling and control, power system dynamics, supplementary power modulation control, VSC-HVDC transmission, optimal tuning

\footnotetext{
Address correspondence to Elyas Rakhshani, Department of Electrical Engineering, Technical University of Catalonia (UPC), SEER Research Center, GAIA Building, 22 Rambla Sant Nebridi, 08222 Terassa, Barcelona, Spain. E-mail:E-mail: Elyas.rakhshani@gmail.com
} 


\begin{tabular}{ll}
\multicolumn{2}{l}{ NOMENCLATURE } \\
ACE & area control error \\
AGC & automatic generation control \\
apf & area participation factor \\
$\beta$ & frequency bias \\
$f$ & frequency \\
HVDC & high-voltage direct current \\
LFC & load frequency control \\
PCC & point of common coupling \\
$R$ & droop characteristic \\
SPMC & supplementary power modulation controller \\
VSC & voltage source converter \\
PLL & phase locked loop
\end{tabular}

\section{NOMENCLATURE}

ACE area control error

AGC automatic generation control

apf area participation factor

$\beta \quad$ frequency bias
$T_{\mathrm{DC}} \quad$ time constant of HVDC system

$T_{\text {T-G }} \quad$ time constant of GENCO (turbine-governor unit)

$T_{12}$ tie-line synchronizing coefficient between Areas

1 and 2

$T_{\mathrm{p}} \quad$ power system equivalent time constant

$K_{\mathrm{p}} \quad$ power system equivalent gain

$\Delta P_{\text {tie,DC }}$ deviation of modulated power by DC link

$\Delta P_{\text {tie,AC }}$ deviation of AC tie-line power

$\Delta P_{\text {tie,12 }}$ net tie-line power flow between Areas 1 and 2

$\Delta P_{\mathrm{d}} \quad$ load change

$\Delta P_{\mathrm{m}} \quad$ output of each GENCO

$T_{\mathrm{DC}} \quad$ time constant of DC link be very important $[7,8]$. The AC transmission systems have various limitations such as the Ferranti effect in long transmission lines, the capacitive effect of transmission lines, the influence of the line inductance, and the issue of the stability of interconnected power systems $[4,5]$. In long transmission lines based on HVAC cables, the problem of reactive power due to the HVAC cable charging is a critical issue. In addition, the length of these cables limits the ability of active power transmission, which decreases as the length of the line increases [9]. On the other hand, the HVDC transmission system has many advantages, which can provide solutions to existing problems in AC systems and thus increase the stability of the system $[5,6]$. VSC-HVDC systems provide better grid connection solution for weak grids and unsynchronized AC systems. The VSC stations of the HVDC system can work in both directions; it provides efficient voltage control with a better power flow controllability [9-11]. Challenging projects usually include integration of large-scale offshore wind farms, which are located far from shore for instance in case of North Sea, or the integration of solar energy from the Middle East and North Africa to their main grid [12]. In those projects, it is claimed that DC transmission systems are more technically and economically convenient than $\mathrm{AC}$ transmission systems [12]. In parallel with increasing application of HVDC links, the coordination of DC link with the rest of $\mathrm{AC}$ power grid will be very important, and AGC system is one of the tools that can facilitate the coordination of HVDC system with the rest of AC areas.

The requirements in the frequency control and the net power interchange in a multi-area interconnected power system are settled by the AGC $[13,14]$. Its concept was discussed in many literatures, and different control strategies are applied for better performance of the AGC systems [15-20]. The main goal of the LFC in a power system is to maintain the frequency of each area and tie-line power flow (in interconnected system), within specified tolerance, by adjusting the power outputs of the generators to accommodate the fluctuating load demands [13, 14]. By means of taking advantage of the fast power control capability of VSC-HVDC systems together with the implementation of a suitable supplementary controller to modulate the DC power transfer, based on AC system signals, it would be feasible to simultaneously achieve the main objectives of the AGC. Parallel AC/DC links are one of the main promising solutions of this type of coordination for improving the dynamic performance of the system [21].

In the literature, the AGC of a two-area power system interconnected via AC/DC parallel links is carried out with different control approaches to bring better dynamic responses [21, 22]. However, none of them considered a complete dynamic model of DC link for AGC application. In the presented research work, the part related to PLL dynamics and frequency measurements of VSC-HVDC stations is also missing.

The PLL is typically utilized for angle reference generation for the traditional line-commutated converter (LCC)based HVDC and the emerged VSC-based HVDC transmission applications [23]. This angle reference is used for generating the firing pulses to the insulated-gate bipolar transistor (IGBT) switches of the VSC stations. Results of the recent research work show that the gains of the PLL parameters can significantly affect the operation of the VSC-HVDC converter stations. The efficiency and maximum power limits of VSCHVDC system can be affected by PLL PI controller gains and the system damping $[23,24]$.

In this paper, in order to improve the LFC performance and avoid HVAC limitations, a new supplementary modulation controller (SMC) for a VSC-HVDC system proposed considering the dynamic model of frequency measurements in LFC 


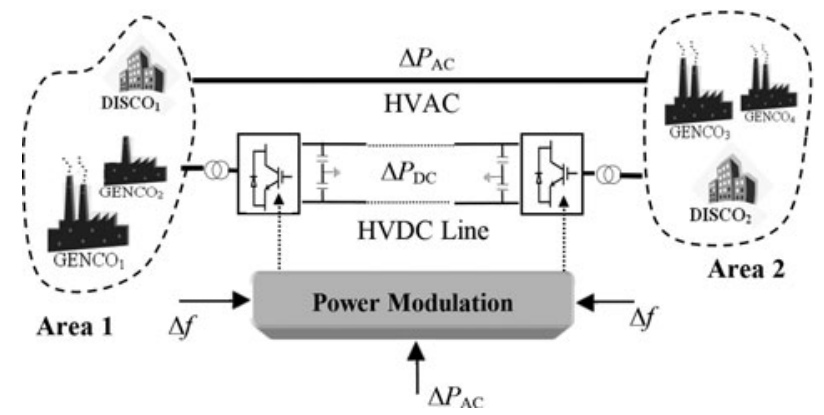

FIGURE 1 The configuration of the power system with added VSC-HVDC link.

interconnected system. All the parameters of proposed modulation controller are tuned by Genetic Algorithm (GA) and Simulated Annealing (SA) intelligent methods based on minimization of a defined objective function in AGC model. Furthermore, in order to include the dynamic effects of PLL and the delays in the measurements, a more detailed model is considered by adding additional transfer functions for modeling of the dynamic of the PLL.

\section{INTERCONNECTED AC/DC SYSTEM}

As shown in Figure 1, the analyzed system in this paper is a two-area system with one parallel AC/DC link. Each area contains two generation companies (GENCOs) and one Distributed company (Disco). The control strategy is based on the minimization of the ACE in each area. The equivalent model of this system can be represented in differential form as follows:

$$
\begin{aligned}
& \mathrm{ACE}_{1}=\beta_{1} \Delta f_{1}+\Delta P_{12} \\
& \mathrm{ACE}_{2}=\beta_{2} \Delta f_{2}+\Delta P_{21}
\end{aligned}
$$

where, $\beta_{1}$ and $\beta_{2}$ are the frequency biases for each area and $\Delta P_{12}$ is the total tie-line power exchange between two areas:

$$
\begin{gathered}
\Delta P_{\text {tie, } 12}=\Delta P_{\text {tie }, \mathrm{DC}}+\Delta P_{\text {tie }, \mathrm{AC}} \\
\Delta f=f_{\text {actual }}-f_{\text {scheduled }}
\end{gathered}
$$

Considering $f$ as system frequency, while $\Delta P_{\mathrm{AC}}$ and $\Delta P_{\mathrm{DC}}$ are the AC and DC tie-line power flow, respectively [16].

For modeling of interconnections between different areas in multi-area AGC system, the tie-line power change between two interconnected areas (Areas 1 and 2) is presented as follows:

$$
\Delta P_{\mathrm{tie}, \mathrm{AC}}=\frac{T_{12}}{S}\left[\Delta \omega_{1}-\Delta \omega_{2}\right]
$$

where $T_{12}$ is the synchronization coefficient between areas. Therefore, the state-space presentation for the frequency deviation for $i$ th area $(i=1,2)$ can appear as follows:

$$
\begin{aligned}
\Delta \omega_{1} & =\frac{K_{p 1}}{1+s T_{p 1}}\left[\Delta P_{m 1}+\Delta P_{m 2}-\Delta P_{L 1}-\Delta P_{\text {tie }, 12}\right] \\
\Delta \omega_{2} & =\frac{K_{p 2}}{1+s T_{p 2}}\left[\Delta P_{m 3}+\Delta P_{m 4}-\Delta P_{L 2}+\Delta P_{\text {tie }, 12}\right]
\end{aligned}
$$

where $\Delta P_{L i}(i=1,2)$ is local load deviation, $K_{p i}$ is the power system gain, $T_{p i}$ is the power system time constant, $\Delta P_{m k}(k=1: 4)$ is the output of generation units and $K_{p i}=$ $\frac{1}{D_{\mathrm{sys}-i}}, T_{p i}=\frac{M_{\mathrm{sys}-i}}{D_{\mathrm{sys}-i}}=\frac{2 H_{\mathrm{sys}-i} / \omega_{0}}{D_{\mathrm{sys}-i}}$.

Considering that $H_{\mathrm{sys}-i}$ and $D_{\mathrm{sys}-i}$ are inertia and damping, respectively. The rest of the variables can be defined as follows:

$$
\begin{aligned}
& \Delta P_{m 1}=\frac{1}{1+s T_{t g, 1}}\left[\frac{\Delta \omega_{1}}{R_{1} \times 2 \pi}-K_{I 1} \operatorname{apf}_{1} \Delta P_{\mathrm{ref} 1}\right] \\
& \Delta P_{m 2}=\frac{1}{1+s T_{t g, 2}}\left[\frac{\Delta \omega_{2}}{R_{2} \times 2 \pi}-K_{I 2} a p f_{2} \Delta P_{\mathrm{ref} 1}\right] \\
& \Delta P_{m 3}=\frac{1}{1+s T_{t g, 3}}\left[\frac{\Delta \omega_{3}}{R_{3} \times 2 \pi}-K_{I 3} a p f_{3} \Delta P_{\mathrm{ref}} 2\right] \\
& \Delta P_{m 4}=\frac{1}{1+s T_{t g, 4}}\left[\frac{\Delta \omega_{4}}{R_{4} \times 2 \pi}-K_{I 4} a p f_{4} \Delta P_{\mathrm{ref} 2}\right]
\end{aligned}
$$

where $R_{k}(k=1: 4)$ is considered as droop for each GENCO, $T_{t g}$ is the overall time constants of turbine and governor in each GENCO and is equal to $\left(T_{t i k}+T_{g i k}\right)$ [5]. The reference of generation units in $i$ th area will be based on ACE and could be considered like this:

$$
\begin{aligned}
& \Delta P_{\text {ref } 1}=\frac{\mathrm{ACE}_{1}}{s}=\frac{1}{s}\left[\frac{\beta_{1}}{2 \pi} \Delta \omega_{1}+\Delta P_{\mathrm{tie}, 12}\right] \\
& \Delta P_{\text {ref } 2}=\frac{\mathrm{ACE}_{2}}{s}=\frac{1}{s}\left[\frac{\beta_{2}}{2 \pi} \Delta \omega_{2}-\Delta P_{\text {tie }, 12}\right]
\end{aligned}
$$

The amount of DC power exchange $\left(\Delta P_{\text {tie,DC }}\right)$ will be based on SPMC, which is explained in Section 3.

\section{DESIGN OF SUPPLEMENTARY POWER MODULATION CONTROLLER FOR THE VSC-HVDC LINK}

A novel designed bidirectional power modulation controller is proposed to control the DC power flow through the VSCHVDC link in a two-area power system. The DC link in this case, thanks to the utilization of VSC-HVDC technology, acts as a bidirectional line that includes two converter stations, one performing as a rectifier at the sending side, and the other performing as an inverter at the receiving end [6, 7]. In the first part of this section, general information about the VSCHVDC system structure applied in this case is reviewed, and 


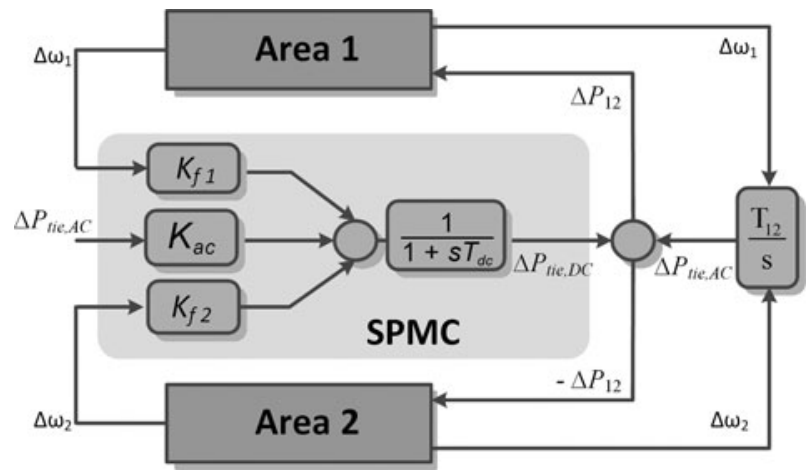

FIGURE 2 The schematic diagram of applying a SPMC to the power system with parallel HVAC and VSC-HVDC links.

finally, the new design based on including a SMC for a bidirectional VSC-HVDC system in a multi-area power system is explained.

\subsection{VSC-HVDC System}

A general configuration of the VSC-HVDC system is shown in Figure 1. As depicted in this figure, it consists of four basic parts such as DC link capacitors, $\mathrm{AC} / \mathrm{DC}$ and $\mathrm{DC} / \mathrm{AC}$ converters, transformers, and a DC cable. Industrial plants are connected to the VSC-HVDC system at a point of common coupling (PCC) [6].

\subsection{Supplementary Power Modulation Controller}

The block diagram of the supplementary power modulation controller for modeling of the VSC-HVDC for LFC study is shown in Figure 2.

This controller modulates both frequency and active power by processing the frequency signal obtained from the local measurements. The objective of this study is to damp the critical low frequency inter-area or local modes that can affect the stability of the whole system during load changes. The power flow through the VSC-HVDC link is modulated based on the measured frequency at the two sides and based on the $\mathrm{AC}$ power flow rate of change between the interconnected control areas.

In this study, the dynamics of HVDC power electronic parts are neglected because the time constant of electronic parts is much smaller than that involved in dynamic analysis of largescale power system. Each converter station can be modeled as a first-order transfer function consisting of a proper time constant, which is related to control blocks presented in Figure 3. For an HVDC system with two VSC stations, the second-order transfer function will be approximated by the equivalent firstorder transfer function, imitating the overall time response of

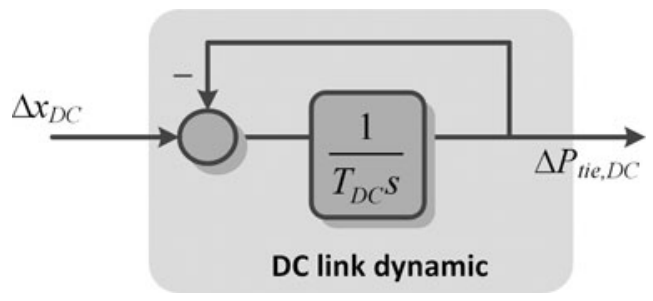

FIGURE 3 Block diagram of the HVDC system.

HVDC system as follows:

$$
\begin{aligned}
\frac{1}{1+s T_{1}} \times \frac{1}{1+s T_{2}} & =\frac{1}{1+\left(T_{1}+T_{2}\right) s+\left(T_{1} T_{2}\right) s^{2}} \\
& \cong \frac{1}{1+s T_{\mathrm{DC}}}
\end{aligned}
$$

where $T_{1}$ and $T_{2}$ are the time constants of converters and $T_{\mathrm{DC}}$ is the equivalent time constant of the overall HVDC control system $\left(T_{\mathrm{DC}}=T_{1}+T_{2}\right)$.

Therefore, the incremental power flow through the HVDC transmission system can be modeled by a linear first-order model with a proper time constant as follows:

$$
T_{\mathrm{DC}} \frac{d \Delta P_{\text {tie, } \mathrm{DC}}}{d t}=\Delta x_{\mathrm{DC}}-\Delta P_{\mathrm{tie}, \mathrm{DC}}
$$

where $\Delta x_{\mathrm{DC}}$ is the reference control signal of DC power and $\Delta P_{\text {tie, DC }}$ will be the real DC power flow through the system. In this paper, SMC is designed not only to improve the performance of power system during load changes, also to increase the capability of the steady-state power transferring between the two AC interconnected systems.

A major feature of such supplementary controller is that it utilizes signals obtained from local measurements. These measurements will be used to synthesize the control signal for operation of higher level control of HVDC coordination, leading to damp the critical inter-area modes [4].

If the frequency deviations are monitored, it can be used as a control signal for the VSC-HVDC unit to control the power flow by changing the duty cycles of bidirectional converters, as explained in $[7,18]$. Since the VSC-HVDC is a bidirectional line, the frequency in both areas must be monitored. Therefore, a feedback scheme is configured using two measurable signals, frequency deviations for each area and the power deviation in the AC tie-line transmission link. The proposed coordinated control strategy for this kind of VSC-HVDC link can be written as follows:

$$
\Delta x_{\mathrm{DC}}=K_{f 1} \Delta \omega_{1}+K_{f 2} \Delta \omega_{2}+K_{\mathrm{AC}} \Delta P_{\mathrm{tie}, \mathrm{AC}}
$$

where the $\Delta X_{\mathrm{DC}}$ is the control signal for the DC link, while $K_{f 1}, K_{f 2}$, and $K_{\mathrm{DC}}$ are the control gains. The HVDC link can 


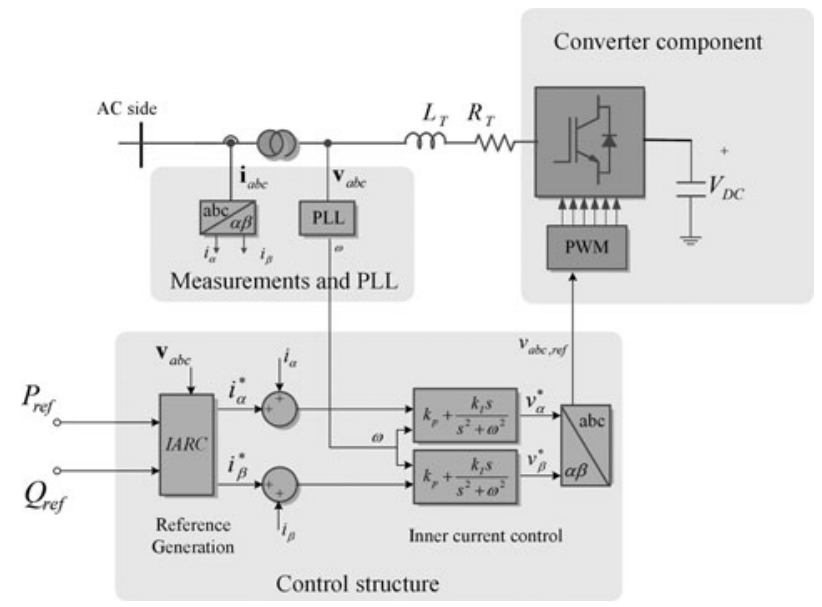

FIGURE 4 A typical control structure of grid-connected converters.

be presented in Laplace domain as follows:

$$
\begin{aligned}
\Delta P_{\mathrm{tie}, \mathrm{DC}} & =G_{p} \Delta x_{\mathrm{DC}} \\
G_{p} & =\frac{1}{1+s T_{\mathrm{DC}}}
\end{aligned}
$$

where $T_{\mathrm{DC}}$ is the time constant of the VSC-HVDC system.

\section{DYNAMIC EFFECTS OF FREQUENCY MEASUREMENTS}

\subsection{Model of PLL Dynamics}

The PLL is the most commonly utilized method for synchronizing the converter to the grid and measuring the grid frequency. Its dynamics can be approximated by a first-order or second-order model $[24,25]$. A general control structure of grid-connected converter with DC link and PLL is shown in Figure 4. As shown in Figure 4, reference values for active and reactive powers are coming from high-level control actions like droop frequency control. Related current references can be obtained based on the concept of Instantaneous ActiveReactive Control in the reference generation block [25]. The inner current loop controller is used for providing the reference voltage for converter. The angle of the grid voltage

(a)

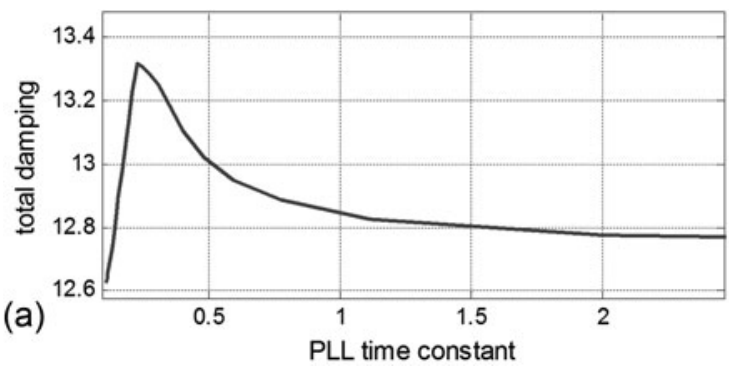

is provided by a PLL. This PLL can be used for estimating the frequency. This estimation is vital for proper action of the inner current controller. The power references are generated by the higher level control of the interconnected power system.

In this study, in order to evaluate the dynamic effects of PLL and the delay in the measurements, a more detailed model is considered by adding additional transfer functions that model the dynamics of PLL and delayed measurements in the HVDC dynamic transfer function. A proper secondorder transfer function imitating the dynamics of a PLL can be written in a normalized way as follows:

$$
H_{\mathrm{PLL}}(s)=\frac{2 \zeta \omega_{n} s+\omega_{n}^{2}}{s^{2}+2 \zeta \omega_{n} s+\omega_{n}^{2}}
$$

where

$$
\omega_{n}=\sqrt{\frac{k_{p}}{T_{i}}} \text { and } \zeta=\frac{\sqrt{k_{p} T_{i}}}{2}
$$

$k_{p}$ and $T_{i}$ are the gain and time constant of the filter used in the PLL block.

The approximated time constant of this second-order function can be considered $\tau=\frac{1}{\zeta \omega_{n}}$ for $1 \%$ of steady-state response [25]. In Figure 5, the total damping and frequency of oscillations for the studied system are presented for different values of PLL time constant. It is clear that the time constants less than $0.5 \mathrm{sec}$ will bring better responses. Therefore, it is assumed that $\zeta$ is equal to 1.5 and $\omega_{n}$ is equal to $3.5 \mathrm{~Hz}$. It means that the time constant of PLL, for this study, is around $0.2 \mathrm{sec}$, which will bring an acceptable performance for the system.

\subsection{System Modeling Considering the PLL Measurement Dynamics}

Although several techniques are proposed for estimating the frequency, PLL is the most commonly used in practice. In this paper, the model presented in Figure 2 is modified by adding two second-order transfer functions for studying PLL dynamics. The modified model of parallel AC/DC interconnection with PLL is shown in Figure 6. As explained earlier, in the second-order transfer function, there is one zero in the

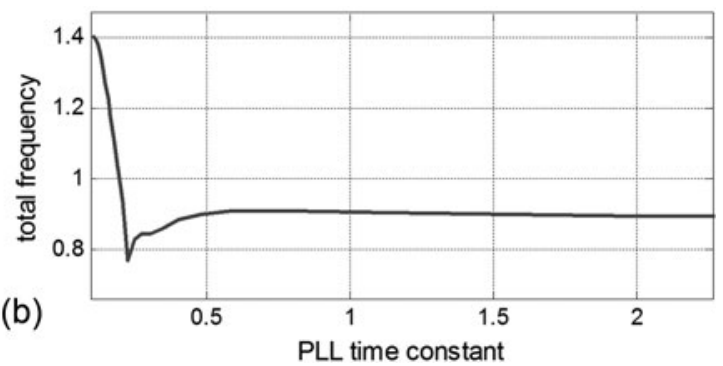

FIGURE 5 Effect of PLL time response on the system characteristics: (a) total damping of modes and (b) total frequency of modes. 


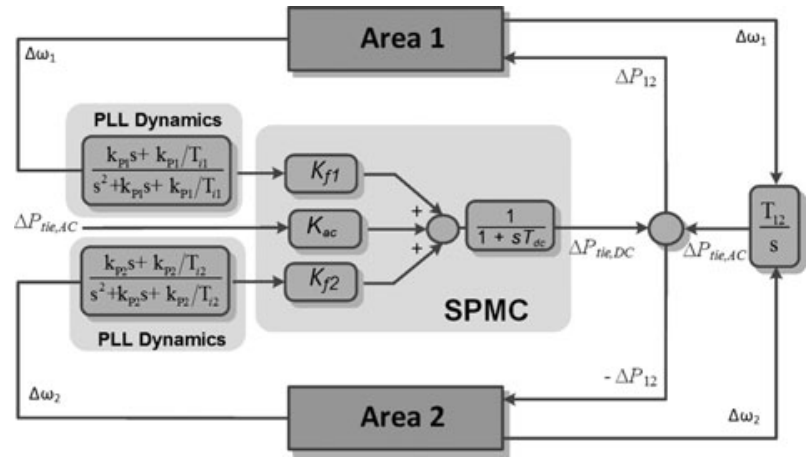

FIGURE 6 The schematic diagram of parallel AC/DC system with PLL measurements.

numerator. This zero will exhibit some overshoots in the system responses.

In order to analyze the system including PLL, all the equations should be transferred into the state-space equation of global two-area system. The relationship between input and output signals in this second-order system could be identified as follows:

$$
\dot{y}+2 \zeta \omega_{n} \dot{y}+\omega_{n}^{2} y=2 \zeta \omega_{n} \dot{u}+\omega_{n}^{2} u
$$

The input signal $u(t)$ is the grid frequency $\Delta \omega_{i}$, which is related to other state of the global multi-area system, and the output signal will consist of two states variables.

$$
\Delta y=\left[\begin{array}{l}
\Delta x_{1, P} \\
\Delta x_{2, P}
\end{array}\right]
$$

Based on classic control concepts, this second-order system can be represented by a set of two linear state equations.

$$
\begin{aligned}
{\left[\begin{array}{c}
\Delta \dot{x}_{1, P} \\
\Delta \dot{x}_{2, P}
\end{array}\right]=} & {\left[\begin{array}{cc}
0 & 1 \\
-\omega_{n}^{2} & -2 \zeta \omega_{n}
\end{array}\right]\left[\begin{array}{l}
\Delta x_{1, P} \\
\Delta x_{2, P}
\end{array}\right] } \\
& +\left[\begin{array}{cc}
0 & 0 \\
2 \zeta \omega_{n} & \omega_{n}^{2}
\end{array}\right]\left[\begin{array}{l}
\Delta \dot{u} \\
\Delta u
\end{array}\right]
\end{aligned}
$$

Therefore, considering the input signals $\left(\Delta \omega_{i}\right)$ for $i$ th area $(i=1: 2)$ of two-area interconnected system, complete state equations of these new states can be stated as follows:

$$
\Delta \dot{x}_{1, P i}=\Delta x_{1, P i}
$$

$$
\begin{aligned}
\Delta \dot{x}_{2, P i}= & \beta_{1, i} \Delta \omega_{i}+\beta_{2, i} \Delta P_{m j}+\beta_{3, i} \Delta P_{\mathrm{tie}, \mathrm{AC}}+\beta_{4, i} \Delta P_{\mathrm{DC}} \\
& +\beta_{5, i} \Delta x_{1, P i}+\beta_{6, i} \Delta x_{2, P i}+\beta_{7, i} \Delta P_{L i}
\end{aligned}
$$

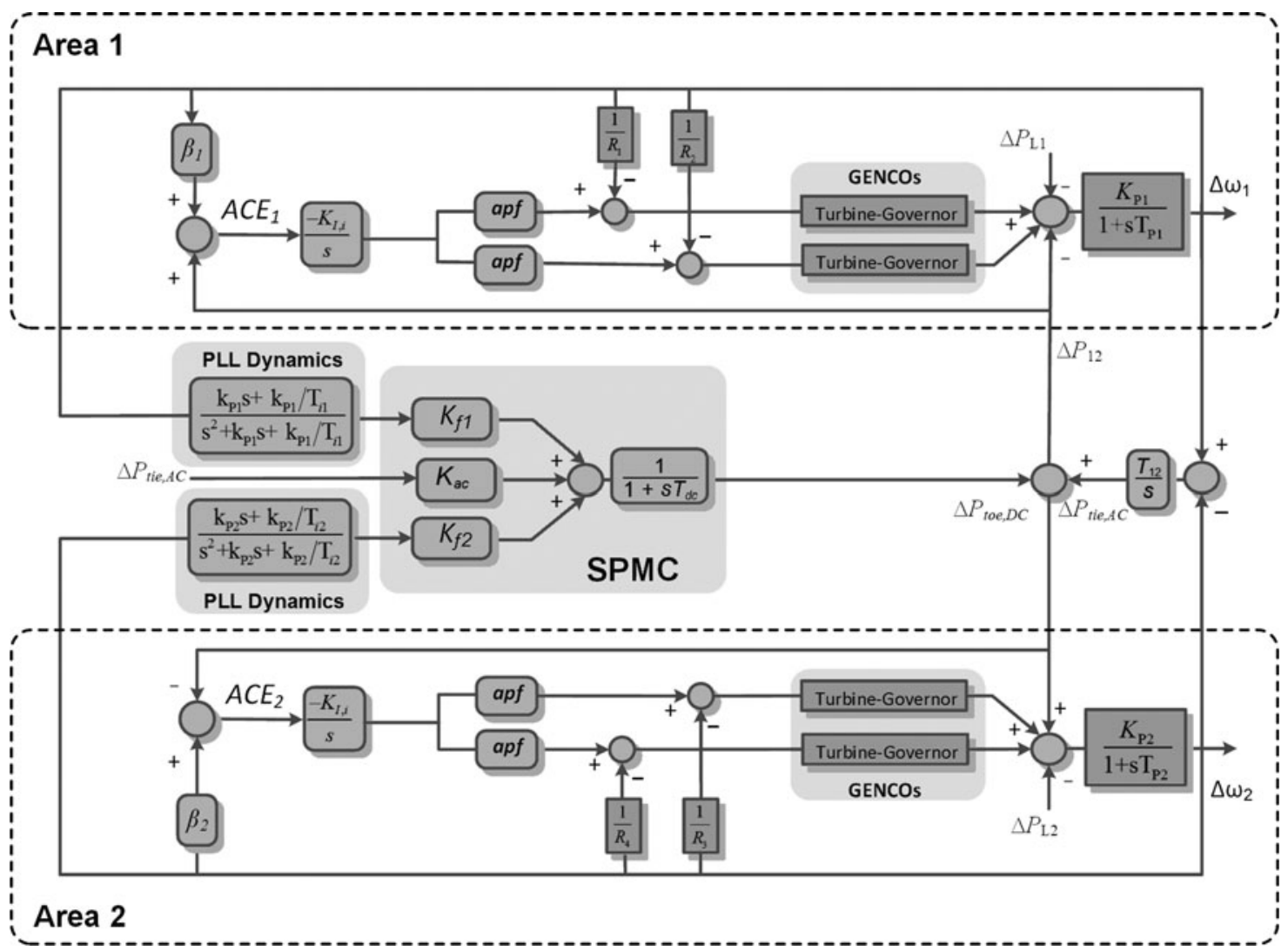

FIGURE 7 Proposed model for the HVDC interconnected system with PLL dynamics. 
where

$$
\begin{aligned}
& \beta_{1, i}=\frac{-2 \zeta_{i} \omega_{n i}}{T_{p i}}+\omega_{n i}^{2}, \beta_{2, i}=\frac{2 \zeta_{i} \omega_{n i} K_{p i}}{T_{p i}} \\
& \beta_{3, i}=\frac{-2 \zeta_{i} \omega_{n i} K_{p i}}{T_{p i}}, \beta_{4, i}=\frac{-2 \zeta_{i} \omega_{n i} K_{p i}}{T_{p i}} \\
& \beta_{5, i}=-\omega_{n i}^{2}, \beta_{6, i}=-2 \zeta_{i} \omega_{n i}, \beta_{7, i}=\frac{-2 \zeta_{i} \omega_{n i} K_{p i}}{T_{p i}}
\end{aligned}
$$

The complete model of two-area system with parallel AC/DC link and PLL dynamics is presented in Figure 7. Therefore, based on presented materials, for adding a new second-order system for each PLL and its communication delays, the linearized mathematical presentation of the studied two-area system can be extracted as follows:

$$
\Delta \dot{x}=A \Delta x+B \Delta u
$$

where $A$ is the new state matrix, considering the dynamics of PLL and measurements in the system with parallel AC/HVDC link control:

$$
A=\left[\begin{array}{ll}
A_{11} & A_{12} \\
A_{21} & A_{22}
\end{array}\right], B=\left[\begin{array}{l}
B_{11} \\
B_{21}
\end{array}\right]
$$

Matrix $A$ has $14 \times 14$ dimension, and $B$ has $14 \times 2$ dimension. All the sub-matrices of (26) are as follows:

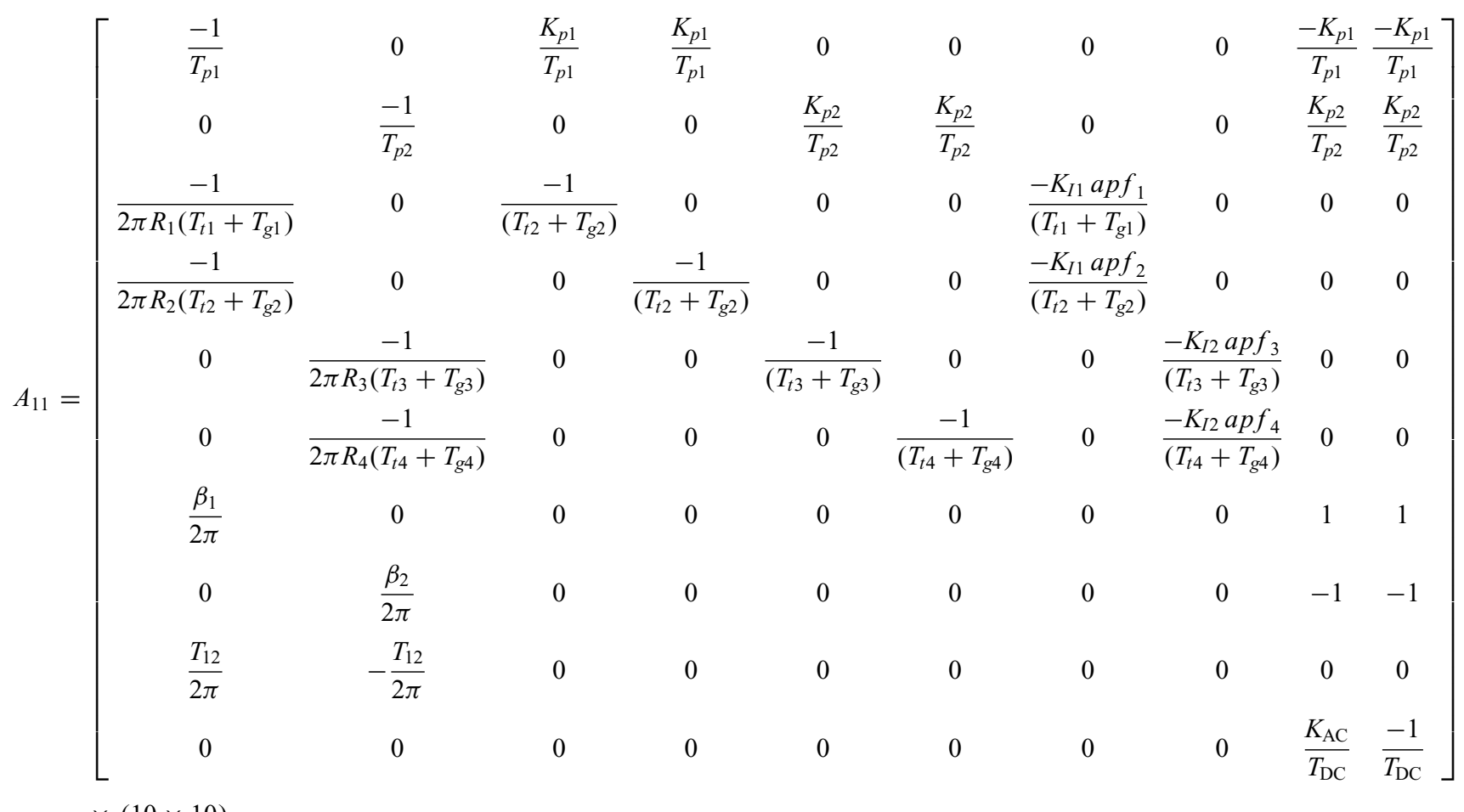

$$
A_{12}=\left[\begin{array}{cccc}
0 & 0 & 0 & 0 \\
0 & 0 & 0 & 0 \\
0 & 0 & 0 & 0 \\
0 & 0 & 0 & 0 \\
0 & 0 & 0 & 0 \\
0 & 0 & 0 & 0 \\
0 & 0 & 0 & 0 \\
0 & 0 & 0 & 0 \\
0 & 0 & 0 & 0 \\
\frac{K_{f 1}}{T_{\mathrm{DC}}} & \frac{K_{f 1}}{T_{\mathrm{DC}}} & \frac{K_{f 2}}{T_{\mathrm{DC}}} & \frac{K_{f 2}}{T_{\mathrm{DC}}}
\end{array}\right]_{(10 \times 4)}
$$$$
A_{21}=\left[\begin{array}{cccccccccc}
0 & 0 & 0 & 0 & 0 & 0 & 0 & 0 & 0 & 0 \\
\beta_{1,1} & 0 & \beta_{2,1} & \beta_{2,1} & 0 & 0 & 0 & 0 & \beta_{3,1} & \beta_{4,1} \\
0 & 0 & 0 & 0 & 0 & 0 & 0 & 0 & 0 & 0 \\
0 & \beta_{1,2} & 0 & 0 & \beta_{2,2} & \beta_{2,2} & 0 & 0 & -\beta_{3,2} & -\beta_{4,2}
\end{array}\right]_{(4 \times 10)}
$$$$
A_{22}=\left[\begin{array}{cccc}
0 & 1 & 0 & 0 \\
\beta_{5,1} & \beta_{6,1} & 0 & 0 \\
0 & 0 & 0 & 1 \\
0 & 0 & \beta_{5,2} & \beta_{6,2}
\end{array}\right]_{(4 \times 4)} \text {, }
$$ 


$$
\begin{aligned}
B_{11} & =\left[\begin{array}{cc}
\frac{-K_{p 1}}{T_{p 1}} & 0 \\
0 & \frac{-K_{p 2}}{T_{p 2}} \\
0 & 0 \\
\vdots & \vdots \\
0 & 0
\end{array}\right]_{(10 \times 2)} \\
B_{21}= & {\left[\begin{array}{cc}
0 & 0 \\
\beta_{7,1} & 0 \\
0 & 0 \\
0 & \beta_{7,2}
\end{array}\right]_{(4 \times 2)} }
\end{aligned}
$$

The control parameters of SPMC in (16) that are implemented in the proposed model with PLL and delay function can be obtained using optimization theory. Usually, it is possible to define a cost function for obtaining the optimum values for these control gains. This issue is discussed in detail in the following section.

\section{PARAMETERS TUNING FOR SPMC BY HEURISTIC METHODS}

This part centered on optimal tuning of modulation controllers for two-area LFC and tie power control using heuristic methods of GA and SA algorithms.

In the optimization methods, the first step in parameter tuning is defining a performance index for optimal search. In this study, the performance index used for optimization is defined by the Integral of Time multiply Absolute Error (ITAE) of the frequency deviation and ACE of both areas. Accordingly, the objective function $J$ is set to be:

$$
J=\int_{0}^{\infty} t\left(\left|\Delta f_{1}\right|+\left|\Delta f_{2}\right|+\left|\Delta \mathrm{ACE}_{1}\right|+\left|\Delta \mathrm{ACE}_{2}\right|\right) d t
$$

Based on this objective function, the optimization problem can be stated as minimization of $J$ subject to these positive parameters:

$$
\begin{aligned}
& K_{f 1}^{\min } \leq K_{f 1} \leq K_{f 1}^{\max } \\
& K_{f 2}^{\min } \leq K_{f 2} \leq K_{f 2}^{\max } \\
& K_{\mathrm{AC}}^{\min } \leq K_{\mathrm{AC}} \leq K_{\mathrm{AC}}^{\max } \\
& \left(K_{f 1}, K_{f 2}, K_{\mathrm{AC}}\right) \geq 0
\end{aligned}
$$

It should be mentioned that the final goal of this intelligent based optimation is control of frequency and inter-area tie power with proper oscillation damping and also obtaining a decent performance under different operating conditions with various load demands.

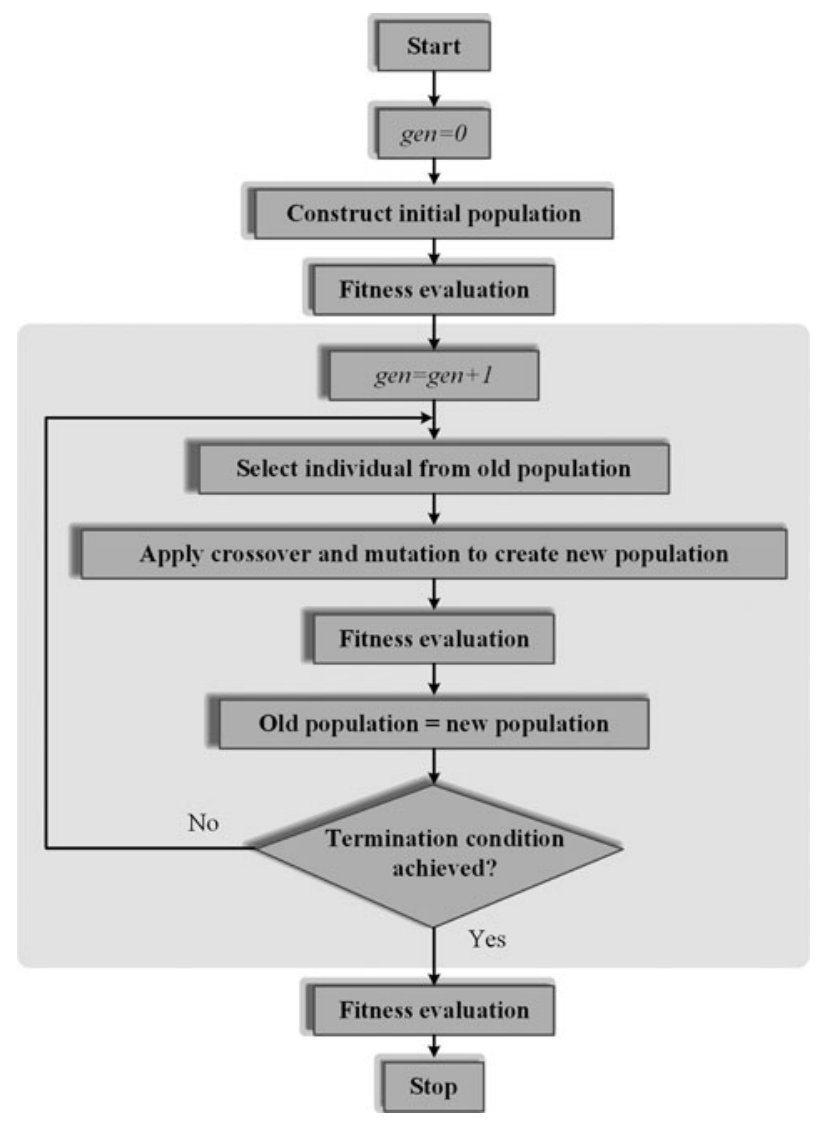

FIGURE 8 Flowchart of GA algorithm.

\subsection{Genetic Algorithm}

GAs are based on the biological gene when a group of solutions evolved through natural selection. Preparing the initial population for the GA algorithm will be based on many chromosomes considering their limits. A flowchart for running the GAs is shown in Figure 8.

The suitable solution for these populations will be achieved through the other genetic operations such as reproduction, crossover, and mutation. Different population members are assigned different reproduction rates proportional to their fitness. It should be noted that the population size should be large enough to provide appropriate genetic structures. After each iteration, the best individual will survive during the optimization process. Additional details on the GA for this application are available in [26].

As shown in Figure 9, the parameters of SPMC are optimized by stimulating a disturbance (step load change) to the system. The parameters with minimum variation on frequency oscillation of both areas are selected via iterative GA process. In this paper, Reference [27] is used as a fitness function in GA search process. The GA parameters that are used in this research are presented in Table 1. 


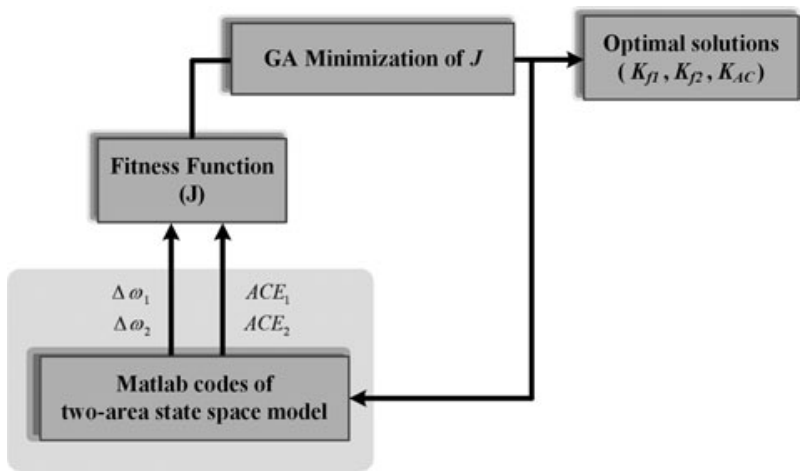

FIGURE 9 Design procedure with GA.

\subsection{Simulated Annealing}

SA method, introduced by Kirkpatrick et al. [27], was applied to find global optimum solutions in the constrained optimization problems. Principal of this technique is based on the formation of crystals in solids during cooling from the melted sate to the low-energy ground state. This method has a kind of analogy with thermodynamics, specifically with the way liquids freeze and crystallize or the way metals cool and anneal. For simulating the annealing process of metals, the material is considered a system of particles. After each neighborhood search, if a better solution can be found, the new configuration replaces the old one. Otherwise, the new one is accepted with the Boltzmann probability of $\mathrm{e}^{-\Delta \mathrm{C} / \mathrm{T}}$ where the $\Delta \mathrm{C}$ is the reduction of the performance and $\mathrm{T}$ is temperature that decreases by time based on a defined decrease factor.

The general structure of SA algorithm is presented in Figure 10. The temperature is considered a control parameter in SA that is decreased gradually as the algorithm proceeds. It determines the probability of accepting a worse solution at any step and is used to limit the extent of the search in a given dimension. The annealing schedule is the rate by which the temperature is decreased as the algorithm proceeds. The slower the rate of decrease, the better the chances are of finding an optimal solution, but with the longer the run time.

The parameters of SA method in this study are presented in Table 2.

\begin{tabular}{l|l} 
Population size & \multicolumn{1}{|c}{100} \\
\hline Selection function & Stochastic uniform \\
Mutation function & Constraint dependent \\
Crossover function & Scattered \\
Migration & Forward \\
Generation & 70
\end{tabular}

TABLE 1. Genetic algorithm parameters

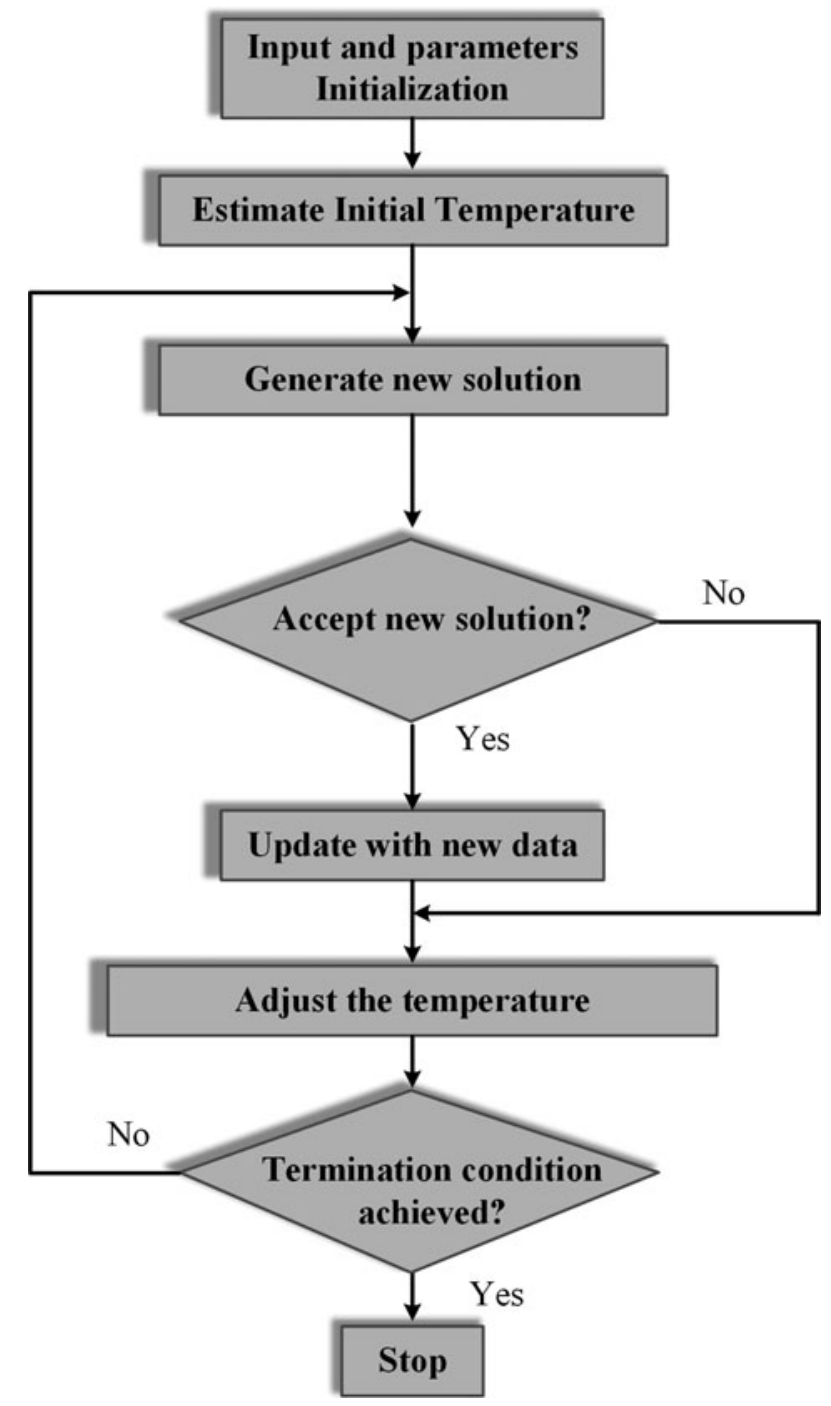

FIGURE 10 Flowchart of SA algorithm.

\section{SIMULATION RESULTS}

In order to evaluate the impacts of the power modulation controller of the VSC-HVDC link against load variations, simulations are performed for one scenario of possible operating conditions and large load demands.

\begin{tabular}{l|c} 
Iterations & 450 \\
\hline Initial temperature & 100 \\
Decreasing factor for & \\
$\quad$ temperature & 0.95 \\
Annealing function & Boltzmann \\
Initial values & {$[0.060 .0010 .06]$}
\end{tabular}

TABLE 2. Simulated annealing parameters 


\begin{tabular}{l|c} 
Parameters & Areas 1 and 2 \\
\hline$T_{T}(\mathrm{sEC})$ & 0.32 \\
$T_{G}(\mathrm{sec})$ & 0.07 \\
$R$ (Hz/p.u.) & 2.10 \\
$K_{P}$ (p.u./Hz) & 102 \\
$T_{P}(\mathrm{sec})$ & 25 \\
$\beta$ (p.u./Hz) & 0.425 \\
$T_{12}(\mathrm{sec})$ & 0.34 \\
$T_{\mathrm{DC}}(\mathrm{sec})$ & 0.2 \\
$K_{\mathrm{I} 1,2}$ & 0.710
\end{tabular}

TABLE 3. Simulated parameters for both areas

In this scenario, the performance of the proposed parallel AC-DC transmission system is compared with that of conventional AC tie-line system. Simulations are performed with MATLAB platform, and the power system parameters are given in Table 3 [4].

In the first step, it is assumed that the load in Area 1 is suddenly increased about 0.03 p.u.MW at $t=5 \mathrm{sec}$ and all generators participate in LFC defined by the following apf:

$$
\begin{aligned}
& a p f_{1}=0.75, a p f_{2}=1-a p f_{1}=0.25 \\
& a p f_{3}=0.5, a p f_{4}=1-a p f_{3}=0.5
\end{aligned}
$$

The results for this case are given in Figures 11-17 and Table 4. The optimization toolboxes from MATLAB are used to solve the present optimization problem [28]. Specifically, we used the Find minimum of constrained nonlinear multi-variable (FMINCON) solver as a classical optimization, which implements the sequential quadratic programming (SQP) method and the interior-point method for nonlinear programming problems. The gradients of the objective and constraint functions are provided as the user-defined functions [29]. This method is one of the conventional methods that

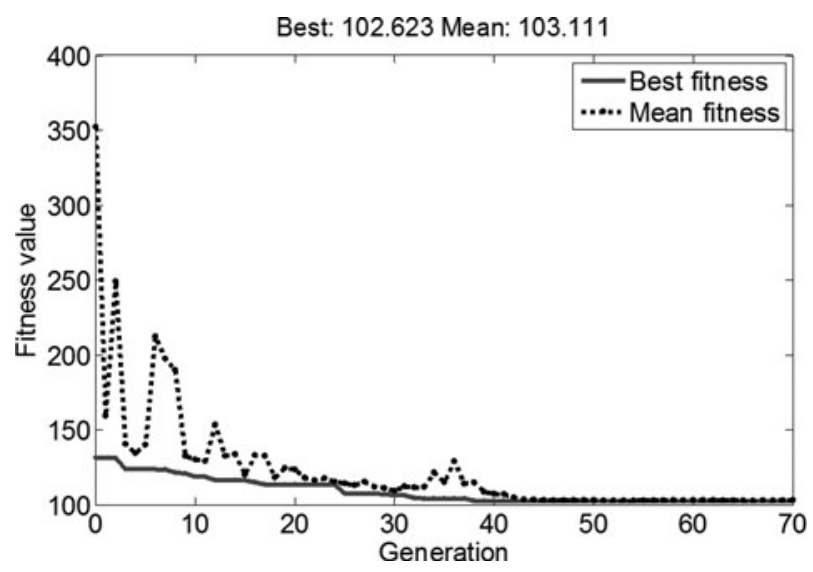

FIGURE 11 Performance index for genetic algorithm.

\begin{tabular}{l|ccc} 
Parameters & GA & SA & Conventional \\
\hline$K_{\mathrm{f} 1}$ & 0.29 & 0.35 & 0.20 \\
$K_{\mathrm{f} 2}$ & -0.08 & -0.07 & 0.085 \\
$K_{\mathrm{AC}}$ & 3.67 & 4.23 & 2.127 \\
Fitness Value & 102.62 & 98.45 & 112.46
\end{tabular}

TABLE 4. Results of control design

are very sensitive to the correct selection of initial values of parameters. This method can be easily trapped in local minimums. All the obtained results from GA and SA are compared with this conventional one. The controller values obtained from the design of the power modulation controller are shown in Table 4.

The heuristic-based approaches are compared with classical optimization approach. As a result, the performance index for the GA and SA, FMINCON algorithms are given in Figures 11-13, respectively. It can be seen from Table 4 and the following figures that the cost function has reduced by using heuristic methods.

The frequency deviations of two areas are presented in Figure 14. In all the figures, there are two main comparisons. The first is between a system with AC interconnection and that with a parallel AC/DC links. The second comparisons in the figures are related to performance evaluation for various optimization techniques for parameter tunings in the proposed AC/DC system.

It is clear that the initial system with standard AC tieline has a huge oscillation, while applying the proposed tuned $\mathrm{AC} / \mathrm{DC}$ interconnection will improve significantly the dynamic responses of the system. As shown in Figure 14, dynamic responses are improved effectively, and the frequency deviation of all areas and the frequency deviations are

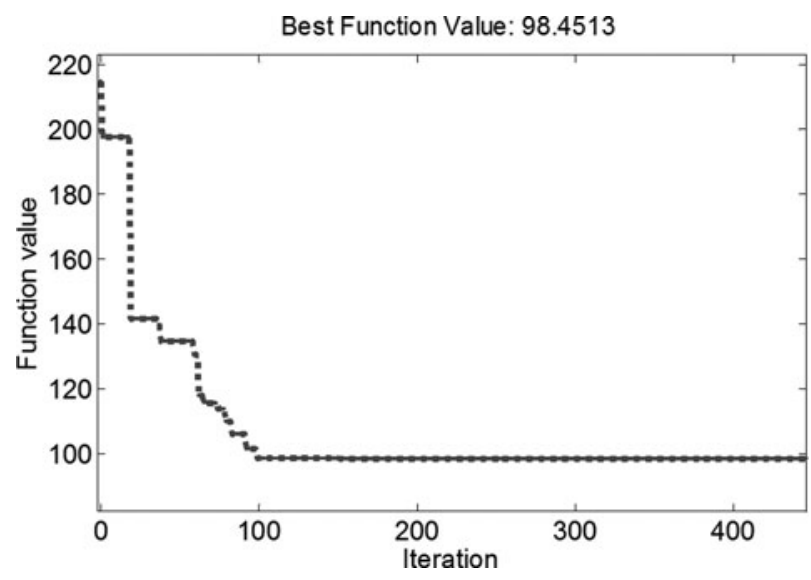

FIGURE 12 Performance index for simulated annealing (SA) algorithm. 


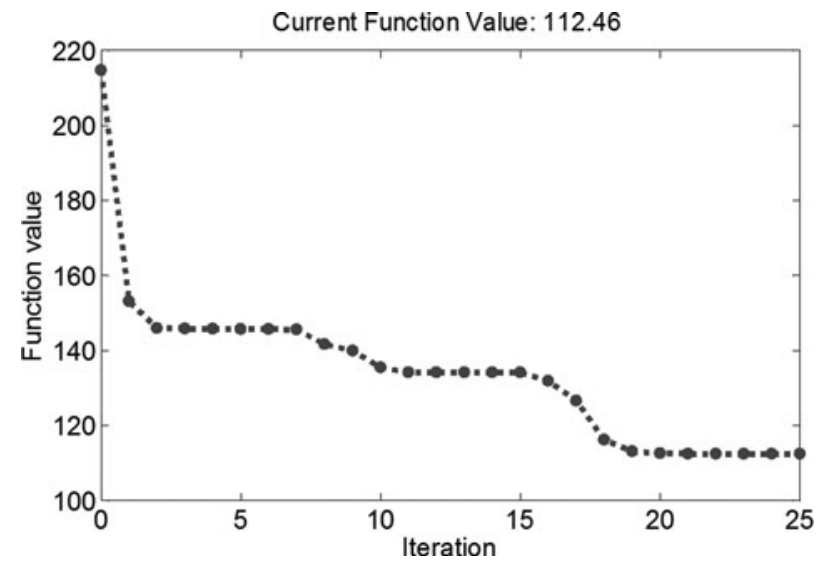

FIGURE 13 Performance index for the classical FMINCON algorithm.

quickly driven back to zero. In addition, it is clear that the effects of heuristic tuning by GA and SA are better than classical FMINCON method. It should be noted that initial values for running the classical FMINCON method made several limitations, and it easily falls into a local minimum solution.

In addition, as shown in Figures 15 and 16, the magnitude of the oscillations in tie-line power is also suppressed by the VSC-HVDC link. Figure 10 shows that the necessary power capacity of power modulation controller is about 0.022 p.u. MW), which is less than the size of load change (0.03 p.u. MW). This result clearly confirms the positive effects of HVDC link to increase the stability and the capacity of transmission line between two areas.

The turbine power deviations of GENCOs are shown in Figures 17(a)-(d). In these figures, the performance of the system for different heuristic based optimization are presented and compared. The actual generated powers of the generators are improved considerably by VSC-HVDC link as depicted in these figures, and according to their apf, the

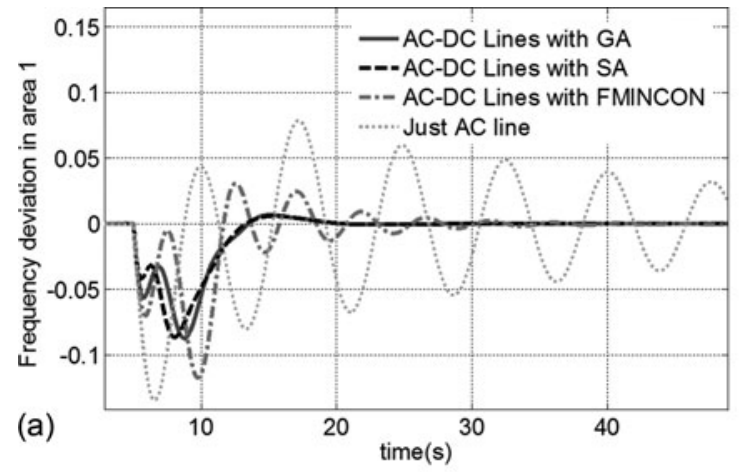

FIGURE 14 Frequency deviation of (a) Area 1 and (b) Area 2.

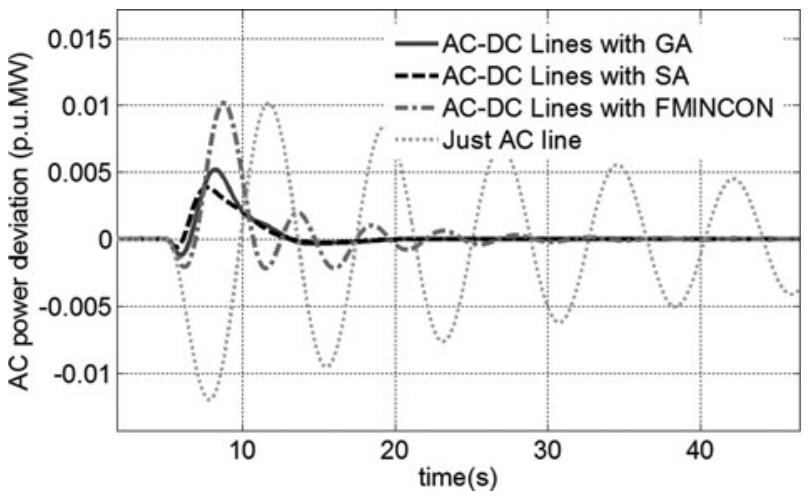

FIGURE 15 AC tie-line power deviation.

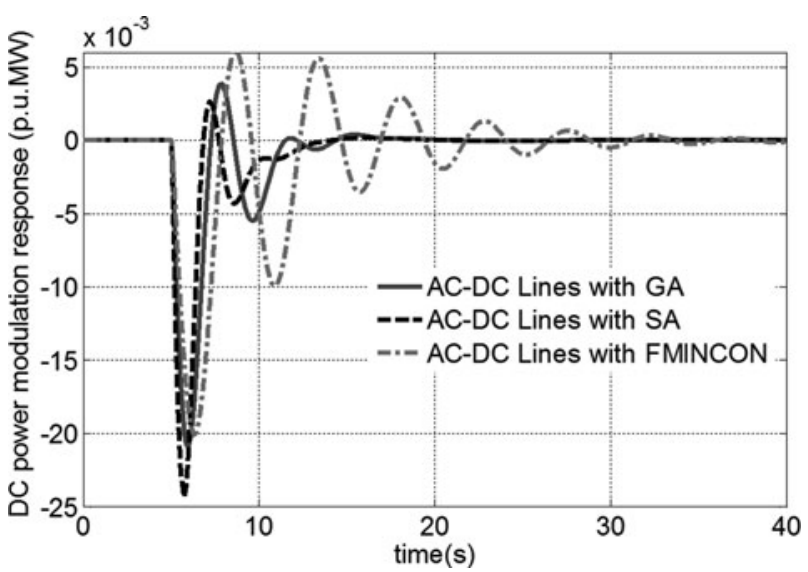

FIGURE 16 DC tie-line power deviation.

powers properly converge to the desired value in the steady state.

Moreover, to examine the effectiveness of the proposed model on response improvements, eigenvalues analysis is presented in Table 5. It is observed that with utilization of a parallel AC/DC model, the oscillations are damped out better, and as a result, the dynamic responses will be improved.

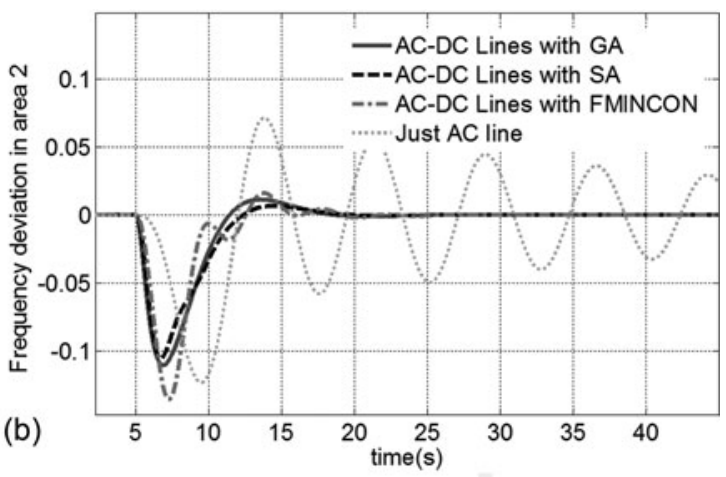



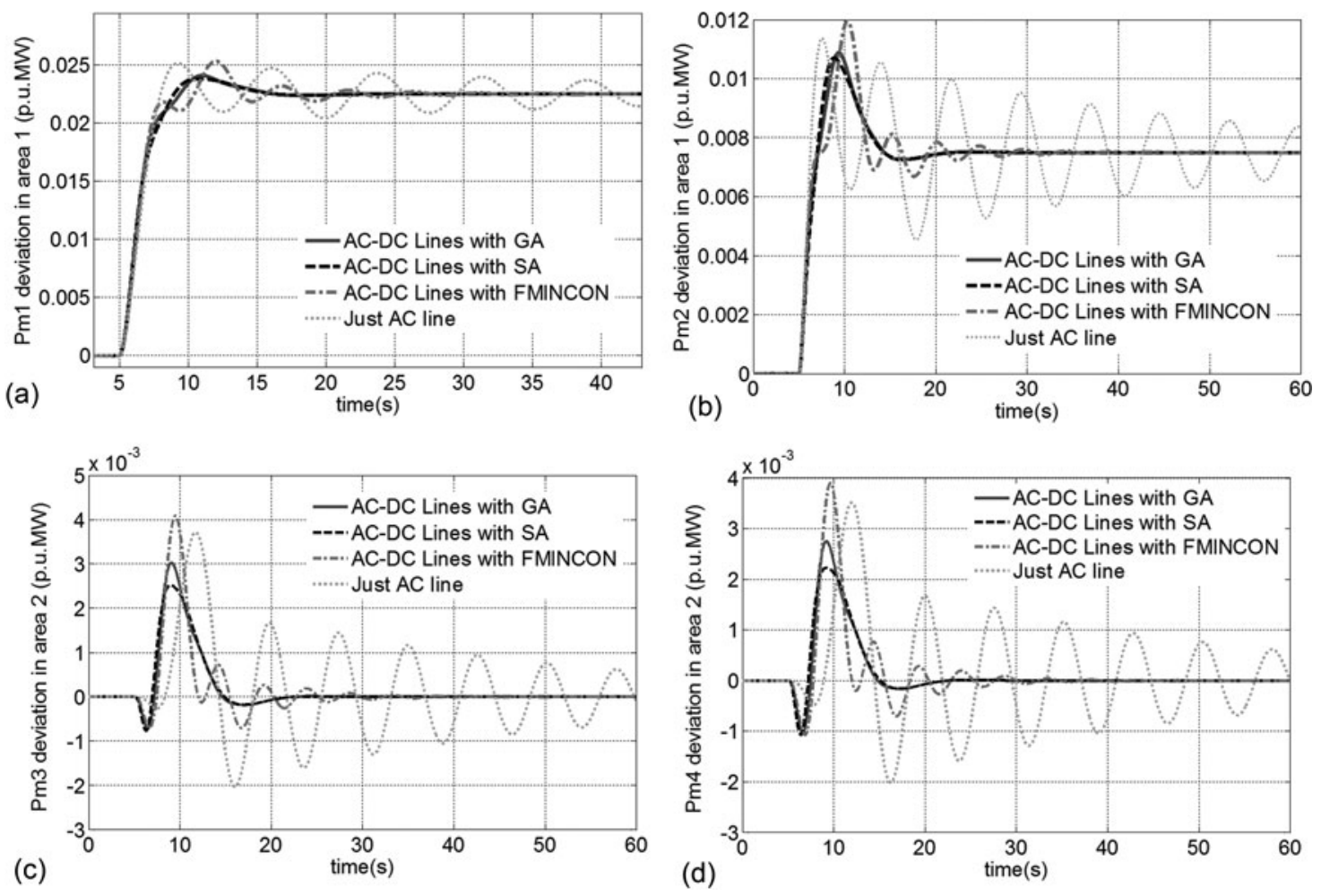

FIGURE 17 The deviation of turbine power of generators: (a) GENCO1, (b) GENCO2, (c) GENCO3, and (d) GENCO4.

\section{CONCLUSION}

In this paper, in order to show the positive effects of VSCHVDC links to the interconnected power systems, a new SMC is proposed for modeling the effects of a bidirectional VSC-HVDC link in parallel to AC tie-line. Then, for parameter tuning of the proposed model, a suitable fitness function with some constraints is used through various optimization techniques. In this part, GA and SA were proposed as heuristic methods and are compared with a classic optimization method. Simulations were performed for two-area power system with one of the possible scenarios with large load variations.

Based on the simulation results and comparisons between HVAC transmissions and HVDC systems, it has been clear that the use of HVDC transmission lines in parallel with HVAC transmission lines increases the strength and the stability of the system. It is clear that by means of the proposed model, a bidirectional power flow control is available, and because the DC interconnection provides an adequate power exchange, reduction of frequency deviations for tested system will be achieved if the control gain is tuned properly. In addition, the results show that heuristic optimization methods have merits compared with the classic FMINCON method, especially when the classic method strongly affects initial parameter values and easily falls into the local minimums.
The results produced by GA and SA are the same. However, in terms of computation time performance, $\mathrm{SA}$ is better than GA.

\section{FUNDING}

This work was partially supported by Spanish Science Ministry of Economy and competitiveness under the project ENE2013-48428-C2-2-R and ENE2014-60228-R. Any opinions, findings, and conclusions or recommendations expressed in this material are those of the authors and do not necessarily reflect those of the host institutions or funders.

\section{REFERENCES}

[1] Kumar, P., and Kothari, D.P., "Recent philosophies of automatic generation control strategies in power systems," IEEE Trans. Power Syst., Vol. 20, No. 1, pp. 346-357, February 2005.

[2] Fang, R., and Hill D.J., "A new strategy for transmission expansion in competitive electricity markets," IEEE Trans. Power Syst., Vol. 18, No. 1, pp. 374-380, Feb. 2003.

[3] Bianchi, F.D., Domínguez-García, J.L., and Gomis-Bellmunt, O., "Control of multi-terminal HVDC networks towards wind power integration: A review," Renew. Sustain. Energy Rev., Vol. 55, pp. 1055-1068, March 2016.

[4] Rakhshani E., Luna A., Rouzbehi K., and Rodriguez P., "Effect of VSC-HVDC on load frequency control in multi-area power 
system," Proceedings of the IEEE Energy Conversion Congress and Exposition (ECCE), pp. 4432-4436, North Carolina, USA, September 2012.

[5] Gemmell, B., Dorn, J., Retzmann, D., and Soerangr, D., "Prospects of multilevel VSC technologies for power transmission," Proceedings of the IEEE/PES Transmission and Distribution Conference and Exposition, pp. 1-16, Chicago, IL, USA, April 2008.

[6] Rouzbehi K., Miranian A., Luna A., and Rodriguez P., "Optimized control of multi-terminal dc grids using particle swarm optimization,” EPE Journal, Vol. 24, No. 2, pp.38-49, Jun. 2014.

[7] Du, C., Agneholm, E., and Olsson, G., "Use of VSC-HVDC for industrial systems having onsite generation with frequency control," IEEE Trans. Power Del., Vol. 23, No. 4, pp. 22332240, October 2008.

[8] Mehrasa, M., Pouresmaeil, E., and Catalao, J.P. S., "Direct Lyapunov control technique for the stable operation of multilevel converter based distributed generation in power grid," IEEE J. Emerg. Sel. Topics Power Electron., Vol. 2, No. 4, pp. 931-941, December 2014.

[9] Padiyar, K.R., Facts Controller in Power Transmission and Distribution, New Delhi, India: New Age International Ltd., 2009.

[10] Sharma, R., Rasmussen, T.W., Jensen, K.H., and Akamatov, V., "Modular VSC converter based HVDC power transmission from offshore wind power plant: Compared to the conventional HVAC system," Proceedings of the IEEE Electric Power and Energy Conference (EPEC), pp. 1-6, Nova Scotia, Canada, August 2010.

[11] Rakhshani, E., Remon, D., Cantarellas, A.M., Garcia, J.M., and Rodriguez, P., "Virtual synchronous power strategy for multiple HVDC interconnections of multi-area AGC systems," IEEE Trans. Power Syst., Vol. 32, 2017. DOI: 10.1109/TPWRS.2016.2592971.

[12] Rouzbehi, K., Miranian, A., Luna, A., and Rodriguez, P., "DC voltage control and power-sharing in multi-terminal dc grids based on optimal dc power flow and voltage droop strategy," IEEE J. Emerg. Sel. Topics Power Electron., Vol. 2, No. 4, pp. 1171-1180, December 2014.

[13] Kunder, P., Power System Stability and Control, New York, McGraw-Hill, 1994.

[14] Jaleeli, N., VanSlyck, L.S., Ewart, D.N., Fink, L.H., and Hoffmann, A.G., "Understanding automatic generation control," IEEE Trans. Power Syst., Vol. 7, No. 3, pp. 1106-1112, Aug. 1992.

[15] Rakhshani, E., Remon, D., Mir Cantarellas, A., and Rodriguez, P., "Analysis of derivative control based virtual inertia in multiarea HVDC interconnected AGC power systems," IET Gener. Transm. Distrib., Vol. 10, No. 6, pp. 1458-1469, April 2016.

[16] Rakhshani, E., and Sadeh, J., "Practical viewpoints on load frequency control problem in a deregulated power system," Energy Convers. Manage., Vol. 51, No. 6, pp. 1148-1156, June 2010.

[17] Rakhshani, E., Remon, D., Cantarellas, A.M., Garcia, J.M., and Rodriguez, P., "Modeling and sensitivity analyses of VSP based virtual inertia controller in HVDC links of multi-area AGC systems," Electr. Power Syst. Res., Vol. 141, pp. 246-263, December 2016.
[18] Ngamroo, I., "A stabilization of frequency oscillations using a power modulation control of HVDC link in a parallel AC-DC interconnected system," Proceedings of the Power Conversion Conference (PCC), Vol. 1, pp. 173-180, Osaka, Japan, September 2002.

[19] Kassem, A.M., and Abdelaziz, A.Y., "Optimal control of an autonomous variable-speed wind generation system based on a bacterial foraging optimization technique," Electr. Power Compon. Syst., Vol. 43, No. 8-10, pp. 1006-1017, June 2015.

[20] Bhateshvar, Y.K., Mathur, H.D., Siguerdidjane, H., and Bhanot, S., "Frequency stabilization for multi-area thermal-hydro power system using genetic algorithm-optimized fuzzy logic controller in deregulated environment," Electr. Power Compon. Syst., Vol. 43, No. 2, pp. 146-156, January 2015.

[21] Bhatti, T.S., "AGC of two area power system interconnected by AC/DC links with diverse sources in each area," Int. J. Elect. Power Energy Syst., Vol. 55, pp. 297-304, February 2014.

[22] Kumar, N.J. V., and Ansari, M.M. T., "A new design of dualmode Type-II fuzzy logic load frequency controller for interconnected power systems with parallel AC/DC tie-lines and superconducting magnetic energy storage unit," Energy, Vol. 89, pp. 118-137, September 2015.

[23] Zhou, J.Z., Ding, H., Fan, S., Zhang, Y., and Gole, A.M., "Impact of short-circuit ratio and phase-locked-loop parameters on the small-signal behavior of a VSC-HVDC converter," IEEE Trans. Power Del., Vol. 29, No.5, pp. 2287-2296, October 2014.

[24] Teodorescu, R., Liserre, M., and Rodriguez, P., Grid Converters for Photovoltaic and Wind Power Systems, New York: IEEEWiley, 2011.

[25] Vasquez, J.C., Guerrero, J.M., Savaghebi, M., Eloy-Garcia, J., and Teodorescu, R., "Modeling, analysis, and design of stationary-reference-frame droop-controlled parallel threephase voltage source inverters," IEEE Trans. Ind. Electron., Vol. 60, No. 4, pp. 1271-1280, April 2013.

[26] Haupt, R.L., and Haupt, S.E., Practical Genetic Algorithms, 2nd ed., John Wiley and Sons Inc., 2004.

[27] Kirkpatrick, S., Gelatt C.D., and Vecchi, M.P., "Optimization by simulated annealing," Science, Vol. 220, No. 4598, pp. 671680, May 1983.

[28] MathWoks, Inc., Matlab. Optimization Toolbox, R2011b, V. 7.13 .

[29] Nocedal, J., and Wright, S., Numerical Optimization, 2nd ed., New York: Springer, 2011.

\section{BIOGRAPHIES}

Elyas Rakhshani was born in Mashhad, Iran, in 1982. He received the B.Sc. degree in power engineering in 2004 and the M.Sc. degree in control systems in 2008 from Islamic Azad University, Iran. Since 2011, he has been pursuing the $\mathrm{Ph}$.D. degree at the Technical University of Catalonia (UPC), Barcelona Tech (SEER research center), Barcelona, Spain, focusing on control and dynamic analyses of multi-area HVDC interconnected power grids in the presence of power 
electronic-based components. Since 2013, he also has been a Researcher with the Research Department, Abengoa Company, Seville, Spain, as a Ph.D. student, working on different projects related to modern power systems. His research interests include power system control, dynamics, and stability; and HVDC control and power converter applications in power systems; and frequency control and optimal intelligent control.

Kumars Rouzbehi received the B.E.E. and M.E.E. (Hons.) degrees in electrical engineering from Islamic Azad University, Iran, in 1998 and 2001, respectively, and the Ph.D. (cum laude) degree in electric energy systems from the Technical University of Catalonia (UPC), Barcelona, Spain, in 2016. He joined the Faculty of Electrical Engineering, IAU, as a Faculty Member in 2004, where he became the Director of the Department of Electrical Engineering. In parallel with teaching and research at IAU, he was the CEO of Khorasan Electric and Electronics Industries Researches Company from 2004 to 2010. His research interests include computational intelligence and its applications in the field of power systems, integration of distributed generation systems to the grid, highvoltage DC technology, and particularly control and operation of multi-terminal DC grids.

Mohamed Atef Elsaharty received the B.Sc. and M.Sc. degrees in electrical and control engineering from Arab Academy for Science, Technology, \& Maritime Transport (AASTMT), Alexandria, Egypt, in 2009 and 2012, respectively. Since 2014, he has been pursuing the Ph.D. degree in electrical engineering at Renewable Electrical Energy System Research Center, Technical University of Catalonia (UPC), Barcelona, Spain. Currently, he is a Senior Teaching Assistant with the Department of Electrical and Control Engineering, AASTMT. His research interests include renewable energy systems modeling, control, and grid interface, linear and non-linear control techniques, distributed control of energy systems, active and passive power filters, power electronics converters, and robotics applications.

Pedro Rodriguez Cortes received the M.Sc. and Ph.D. degrees in electrical engineering from the Technical University of Catalonia (UPC), Barcelona, Spain, in 1994 and 2004, respectively. He was a Postdoctoral Researcher at the Center for Power Electronics Systems, Virginia Tech, Blacksburg, VA, USA, in 2005, and with the Department of Energy Technology, Aalborg University (AAU), Aalborg, Denmark, in 2006. He joined the Faculty of UPC as an Assistant Professor in 1990, where he became the Director of the Research Center on Renewable Electrical Energy Systems, Department of Electrical Engineering. He is currently a part-time Professor with UPC. He was also a Visiting Professor at AAU from 2007 to 2011, and a Co-Supervisor of the Vestas Power Program. In 2011, he joined Abengoa, Seville, Spain, where he is currently the Director of Technology on Power Systems and Power Electronics. He has coauthored 1 book, more than 70 papers in ISI technical journals, and around 250 papers in conference proceedings.

He is the holder of 12 licensed patents. He is an IEEE Fellow for his contributions in the control of distributed generation and an Associate Editor of the IEEE TrAnsaction on Power Electronics. He was the Vice Chair of the Sustainability and Renewable Energy Committee of the IEEE Industry Application Society. He received the Best Technical Letter Award 2012 and the Second Best Paper Award 2012 in the IEEE Transactions on Power Electronics and the Second Paper Award 2014 in the IEEE Journal OF EMERGING AND Selected Topics in Power Electronics. His research interests include distributed power systems, flexible transmission systems, and power conversion. 